\title{
HISTÓRIA DAS IDEIAS LINGUÍSTICAS: POLÍTICAS LINGUÍSTICAS SOBRE LÍNGUAS DE SINAIS
}

\section{HISTORY OF LINGUISTIC IDEAS: LINGUISTIC POLITICS ABOUT SIGN LANGUAGES}

Valeria Fernandes Nunes

Universidade Federal do Rio de Janeiro, UFRJ, Rio de Janeiro, RJ, Brasil

\begin{abstract}
Resumo: Objetivou-se analisar a visibilidade dada às línguas de sinais em políticas linguísticas a fim de conhecer o trajeto de gramatização e de valorização social. Por meio de uma pesquisa bibliográfica, desenvolvida por intermédio de levantamento de referências teóricas, visou-se à compreensão sobre como línguas de sinais de sete países (França, Brasil, Estados Unidos da América, Portugal, Suécia, Japão e China) têm sido descritas em marcos legais. A pesquisa foi fundamentada em reflexôes teóricas da História das Ideias Linguísticas - HIL - à luz das obras de Auroux (1992), Guimarães e Orlandi (2001), Fávero e Molina (2004), Nunes (2010) e Oliveira (2014). Em relação aos Estudos Surdos, analisaram-se as obras de Strobel (2013) e Perlin (2015). Dessa forma, compreendeu-se que leis, decretos e acordos legais, que envolvam a língua de sinais, podem colaborar com o percurso histórico e linguístico dessas línguas.
\end{abstract}

Palavras-chave: Línguas de Sinais; Políticas Linguísticas; História das Ideias Linguísticas.

Abstract: The objective was to analyze the visibility given to sign languages in linguistic policies in order to know the path of grammatization and promotion of social value. By means of a bibliographical research, developed by means of a survey of theoretical references, the work aimed at understanding how sign languages of seven countries (France, Brazil, United States of America, Portugal, Sweden, Japan and China) have been described in statutes. The research was based on theoretical reflections of History of Linguistic Ideas in the light of the works by Auroux (1992), Guimarães and Orlandi (2001), Fávero and Molina (2004), Nunes (2010) and Oliveira (2014). Regarding the Deaf Studies, the works by Strobel (2013) and Perlin (2015) were analyzed. Thus, it was understood that laws, decrees and legal agreements involving sign language can contribute to the historical and linguistic course of these languages.

Keywords: Sign Languages; Linguistic Policies; History of Linguistic Ideas. 


\section{Introduçáo}

As línguas de sinais são utilizadas em diversos países pela comunidade surda. A presença dessas línguas, com recursos gramaticais visuais e espaciais, na sociedade está crescendo. Um dos fatores que contribuem para esse aumento é o fato de os surdos estarem conquistando novos espaços na sociedade, que antes eram ocupados majoritariamente por ouvintes. As conquistas do Povo Surdo, suas identidades múltiplas e sua cultura são retratadas nas artes plásticas, na educação, na história, na literatura, na política e nas línguas de sinais (STROBEL, 2008).

Esta pesquisa fundamentou-se nas reflexões teóricas da História das Ideias Linguísticas - HIL - à luz das obras de Auroux (1992), Guimarães e Orlandi (2001), Fávero e Molina (2004), Nunes (2010) e Oliveira (2014) para apresentar a HIL, a influência da École des Annales, os objetivos dessa corrente linguística e as consideraçóes a respeito do processo de gramatizaçáo através de gramática e dicionários, expondo conceitos acerca desses dois instrumentos linguísticos e de outros instrumentos, que também contribuem para descrever a língua, como diretrizes legais e instituiçôes.

O estudo foi desenvolvido por meio dla investigação de marcos legais relacionados às línguas de sinais de sete países (França, Brasil, Estados Unidos da América, Portugal, Suécia, Japáo e China). Alguns dos fatores que motivaram a seleção dessas línguas foram os seguintes: i - estudo de línguas de sinais com origens diferentes; ii - influências culturais, políticas, sociais e históricas de diferentes partes do mundo (oriente e ocidente); iii - sistemas de escrita das línguas orais dos países selecionados que influenciam as línguas de sinais. Para esta pesquisa, o segundo fator tem maior proeminência tendo em vista que serão analisados normativos legais dos países selecionados.

Cabe ressaltar que a Língua de Sinais Francesa (LSF) possibilitou ao longo da história o surgimento de diversas línguas de sinais, dentre elas a Língua de Sinais Americana (ASL) e a Língua de Sinais Brasileira (Libras). A Língua de Sinais Sueca (LSS) proporcionou a gênesis da Língua Gestual Portuguesa (LGP). Sobre a LSC e a LSJ, ressaltamos que ambas recebem influências linguísticas do sistema de escrita da língua oral de seus respectivos países, isto é, influências de caracteres do chinês na LSC e do Hiragana, do Katakana e do Kanji na LSJ (NUNES, 2018).

Analisaram-se estudos de Strobel (2013) e Perlin (2015) e das seguintes línguas de sinais: Língua de Sinais Francesa, Cloix (2010); Língua de Sinais Americana, Meülder (2015); Língua Brasileira de Sinais, Silva 
(2012); Língua de Sinais Sueca, Svartholm (2014) e Nilsson e Schönström (2014); Língua Gestual Portuguesa, Duarte e Almeida (2003); Língua de Sinais Japonesa, McClue (2013); e Língua de Sinais Chinesa, Yang (2008).

Dessa forma, com base na Declaração de Salamanca (1994), na Declaração Universal dos Direitos Linguísticos (1996) e nas legislaçôes específicas desses países, pretende-se investigar se há orientaçôes sobre políticas linguísticas específicas de línguas de sinais nas diretrizes nacionais aqui estudadas. Além, apoiado nas reflexóes sobre metodologia científica propostas por Gerhard e Silveira (2009), este estudo é uma pesquisa bibliográfica desenvolvida por intermédio de levantamento de referências teóricas.

Para tanto, foram investigadas as seguintes legislaçóes: Lei 91-73 e Lei 2005-102 da França; Emendas da Lei de reabilitação profissional (1965), Lei de reabilitação (1973), Lei de educação para todas as crianças com deficiência (1975), Lei: nenhuma criança deixada para trás (2001) e Lei de telecomunicaçôes (1996) dos Estados Unidos da América; Código do Estatuto Sueco (2009:600); Constituição da República Portuguesa; Lei sobre pessoas com deficiências de 5 de agosto de 2011 do Japão; Lei da República Popular da China sobre a proteção das pessoas deficientes em 1990; e Lei n. ${ }^{0}$ 10.098/2000, Decreto n. ${ }^{0} 6.949 / 2009$, Lei no 10.436/2002; Decreto n. ${ }^{0}$ 5. 626/2005, Lei n. ${ }^{0}$ 12. 319/2010; Decreto 7.387/2010, Lei n. ${ }^{0} 13.0005 / 2014$ e Lei n. ${ }^{0} 13.146 / 2015$ do Brasil.

Ao analisar esses marcos legais, objetivou-se compreender a visibilidade que tem sido dada às línguas de sinais por meio de políticas linguísticas e conhecer também o trajeto de gramatização e de valorização social dessas línguas. Portanto, leis, decretos e acordos legais, que envolvam línguas de sinais e/ou a comunicação com/de surdos, podem colaborar na compreensão do percurso histórico e linguístico das línguas de sinais. Nesta pesquisa, tais registros são investigados como instrumentos linguísticos, conforme propóem os estudos à luz da História das Ideias Linguísticas, que valorizam tais documentos no âmbito dos estudos históricos no campo das ciências da linguagem.

\section{Fundamentação teórica}

Nesta seção, os seguintes tópicos são descritos respectivamente: estudo da História, início da História das Ideias Linguísticas e processo de 
gramatizaçáo. Tradicionalmente, a disciplina História pressupóe o estudo de eventos e de fatos relativos ao passado do ser humano. Consoante a Marc Bloch (2001), a História tem por objeto o homem, pois a História analisa o percurso do homem no tempo. É por meio do tempo que compreendemos fatos históricos, porque somente ao estudar um contexto específico temporal é possível entender acontecimentos.

Lakatos, ao parafrasear Kant, afirma que "a filosofia da ciência sem a história da ciência é vazia; a história da ciência sem a filosofia da ciência é cega" (LAKATOS, 1983, p. 107). Por essa afirmação, compreendemos que a história da ciência pode ser empregada para investigar propostas metodológicas e a filosofia da ciência oferece ao historiador epistemologias que possibilitam a reconstrução racional da história. Tal reconstrução representa a realidade descrevendo o conhecimento sobre nosso passado. A História é entendida como "a ligação entre as concretas particularidades do mundo empírico e os princípios gerais do pensamento" (CONSTANTINO, 2013, p. 286).

Segundo Fávero e Molina (2004), no final do século XIX e início do século XX, começou-se a repensar sobre métodos e abrangência da disciplina História a partir dos ensinamentos das ciências sociais, propondo uma nova História, que dialogasse com outros tempos e outras disciplinas. A inquietaçáo característica das correntes de pensamento do século XX representa

\footnotetext{
recusa ao projeto iluminista, na perplexidade e na incapacidade de compreender um tempo histórico que rompe com o jugo dos antigos, mas que, no entanto, náo alcança um telos de liberdade, perfeiçáo e felicidade, mas de carnificina e miséria; miséria esta, não só material, mas cultural, política e espiritual (OLIVEIRA, 2014, p. 34).
}

Assim, de acordo com Oliveira (2014, p. 34), o estudo do "projeto das Luzes, da Modernidade e de suas ambiguidades, de suas re-significaçôes, bem como de seus objetivos, utopias e ideia de progresso não alcançadas" contribuiu para compreensão de uma crise da Modernidade, um processo de desencantamento, uma reaçáo de recusa manifesta nas correntes de pensamento próprias do século XX, como a École des Annales.

A École des Annales foi um movimento historiográfico proporcionado pelo periódico francês Annales d'histoire économique et sociale cujos estudos enfatizavam as Ciências Sociais e a História. Destacam-se como pioneiros Lucien Febvre e Marc Bloch, na Universidade de Estrarburgo, em 1929. Esse 
movimento gerou mudanças no quadro de pesquisas históricas ao investigar atividades humanas, até então, pouco estudadas, privilegiando métodos que percorrem diversas disciplinas atreladas às Ciências Sociais.

Uma segunda geração, conhecida como Era Braudel, dirigida por Fernand Braudel, marcada por quantificaçóes, por técnicas e pela penetração do marxismo, consistia em situar a história em três escalóes:

na superfície: a história dos acontecimentos, do tempo curto; na meia encosta: uma história conjuntural, que surge ritmo mais lento; e na profundidade: uma história de longa duração (FÁVERO; MOLINA, 2004, p. 136-137).

Segundo Bauer (2012), na proposta de Fernand Braudel, não se tinha como objetivo estudar épocas, mas estruturas particulares que pudessem abandonar a história em fatos isolados e focar em aspectos coletivos, sociais e respectivos do sócio-histórico, substituindo a anterior fixação em indivíduos, elites. A última geração, conhecida como Nouvelle Histoire, apresentou preocupaçóes nas mentalidades, nas vidas cotidianas, com base em representaçóes e interpretaçóes, amplificando a fonte de dados, podendo ser documentos psicológicos, arqueológicos, orais, religiosos. Assim, a partir desse evento, a História buscou identificar

o modo como, em diferentes lugares e momentos, uma determinada realidade social é construída, interpretada e deixada para a posteridade. Nesse sentido, é necessário pensar essa história com um trabalho de representação, isto é, como são traduzidas as posiçōes e interesses dos indivíduos que compõem a sociedade, como pensam que ela é, como agem, ou como gostariam que ela fosse (FÁVERO; MOLINA, 2004, p. 138).

Diante desse pensamento, tem-se o início da História das Ideias Linguísticas com a valorização dos estudos históricos no campo das ciências da linguagem. Dentre os pesquisadores que colaboraram com essa proposta, podemos citar Sylvain Auroux (França). Nos anos 1970, foram criadas condiçóes acadêmico-científicas para que o domínio da História das Ideias Linguísticas fosse desenvolvido.

Tal movimento desses estudiosos acarretou a criação de duas revistas: a Historiographia Linguistica (1974) e a Histoire Épistémologie Langage (1979). Em 1984, foi criada a sociedade inglesa Henry Sweet Society for the History of the Linguistic Ideas, em 1987, sociedade alemã Studienkreis Geschichte der 
Sprachwissenschaft e, em 1991, Beiträge zur Geschichte der Sprachwissenschaft.

Neste artigo, compreendemos a História das Ideias Linguísticas de acordo com Orlandi (2001), que descreve que as análises das ideias linguísticas vinculam-se a "difundir estudos sistemáticos que toquem a questão da história do conhecimento linguístico e da história da língua, articuladamente, explorando novas tecnologias de pesquisas" (ORLANDI, 2001, p. 9). Falar das ideias linguísticas é investigar referências sobre a "definição da língua, a construção de um saber sobre a língua, a produçáo de instrumentos tecnológicos que lhe são ligados e também sua relação com a história do povo que fala" (GUIMARÃES; ORLANDI, 2001, p. 32).

Para Auroux (1992), o processo de gramatização de uma língua "conduz a descrever e instrumentar uma língua na base de duas tecnologias, que ainda hoje são os pilares de nosso saber metalinguístico: a gramática e o dicionário" (AUROUX, 1992, p. 65). Consoante a Antunes (2007), o papel da gramática está relacionado ao controle de determinada língua contra ameaças de desaparecimentos e declínios. Esse controle vai além da preservação da língua. Interesses políticos, econômicos e sociais também estão relacionados, pois o domínio da língua estabelece a comunicação, facilitando, assim, o desenvolvimento de interesses de quem governa.

Dessa forma, "foi sendo atribuído aos compêndios de gramática um papel de instrumento controlador da língua, ao qual caberia conduzir o comportamento verbal dos usuários, pela imposiçáo de modelos ou padróes" (ANTUNES, 2007, p. 36). A criação da gramática, na verdade, tinha por objetivo a regularizaçấo, o estabelecimento de um padrão na língua.

Em relação ao dicionário, Nunes (2010) esclarece que

\begin{abstract}
o dicionário não é algo que estaria na mente das pessoas desde que elas nascem, mas, sim, algo que é produzido por práticas reais em determinadas conjunturas sociais, ou seja, o dicionário é produzido sob certas "condiçôes de produção dos discursos". E as palavras não são tomadas como algo abstrato, sem relaçáo com os sujeitos e as circunstâncias em que eles se encontram, mas sim como resultantes das relaçóes sociais e históricas, relaçóes essas que são complexas e, por vezes, polêmicas ou contraditórias. Assim, o dicionário é visto como um discurso sobre a língua, mais especificamente sobre as palavras ou sobre um setor da realidade, para um público leitor, em certas condiçóes sociais e históricas (NUNES, 2010, p. 6-7).
\end{abstract}

Nunes (2010) também ressalta o papel político e social dos dicionários. Os dicionários sáo produzidos por práticas em conjunturas sociais sob 
condiçôes de produção de discursos. As palavras são resultantes de relaçôes sociais, políticas e históricas. No dicionário, encontram-se registros sobre a língua, especificamente, registro de palavras sobre "um setor da realidade, para um público leitor, em certas condiçôes sociais e históricas" (NUNES, 2010, p. 2). Diante disso, relaçóes sociais, políticas e históricas permeiam a construção desses dois instrumentos linguísticos, gramática e dicionário, moldando o processo de gramatizaçáo da língua.

Orlandi (2002), ao estudar o processo de disciplinarização dos estudos da linguagem no Brasil, descreve outros instrumentos linguísticos que contribuíram na formação da Língua Nacional, Língua Portuguesa. A língua de um país está relacionada à identidade e à autonomia dos sujeitos de uma sociedade. Nomear a língua usada no Brasil de 'língua portuguesa' ou 'língua brasileira' era uma questấo desde o período de colonização no Brasil, que se intensifica no século XIX.

Consoante a Gallo (1993), a forma de produção do saber e de alçamento do sujeito à posição daquele que sabe passa por processos de legitimação determinados historicamente e ideologicamente. Instrumentos linguísticos, tais como gramáticas, dicionários, antologias, programas de ensino (Fausto Barreto), e instituiçóes (Colégio Pedro II, Academia Brasileira de Letras, Biblioteca Nacional) contribuíram no processo de ensino da língua e na relação do brasileiro com sua língua. A produção de instrumentos, como os citados, está relacionada a questóes da língua, da ciência, da sociedade, consequentemente, questóes políticas pois

\begin{abstract}
ao mesmo tempo que a linguística se constitui como ciência, a questáo da língua é afetada pela relação do sujeito com o Estado. As políticas gerais de um país manifestam esta inter-relação cuja forma mais visível é a formulação das Políticas Linguísticas: as invasōes, as exclusões, as hierarquias. A noção de política linguística adquire aqui outro sentido. Quando se define que língua falamos, com que estatuto ou quando se determina este ou aquele modo de acesso a esta língua - pelo ensino, pela produçấo dos instrumentos linguísticos, pela leitura das publicaçóes, pelos rituais de linguagem, pela legitimidade dos acordos, pela construção das instituiçóes linguísticas praticamos concomitantemente diferentes formas de políticas da língua (GUIMARÃES; ORLANDI, 2001, p. 36).
\end{abstract}

Dessa forma, atos políticos, como criação de leis e decretos nacionais, influenciam nas relaçóes de uma língua e seus usuários. Muitas vezes, descrevendo como essa língua será usada, ensinada, vista em uma sociedade, pois atos legais sáo instrumentos de poder social que colaboram para a 
descrição linguística de uma língua.

A Declaração de Salamanca (1994), a Declaração Universal dos Direitos Linguísticos (1996) e legislaçóes específicas de outros países sobre as línguas de sinais aqui estudadas e abordadas são exemplos desses instrumentos. A Declaraçáo de Salamanca (1994) faz referência à educação de surdos e esclarece que a linguagem de signos ${ }^{1}$ deveria ser considerada como meio de comunicação dos surdos, conforme descrito na seção sobre o Novo Pensar em Educação Especial, no item 19:

Políticas educacionais deveriam levar em total consideração as diferenças e situaçôes individuais. A importância da linguagem de signos como meio de comunicação entre os surdos, por exemplo, deveria ser reconhecida e provisão deveria ser feita no sentido de garantir que todas as pessoas surdas tenham acesso à educaçẫo em sua língua nacional de signos. Devido às necessidades particulares de comunicação dos surdos e das pessoas surdas/cegas, a educaçáo deles pode ser mais adequadamente provida em escolas especiais ou classes especiais e unidades em escolas regulares (DECLARAÇÃO DE SALAMANCA, 1994).

Já a Declaração Universal dos Direitos Linguísticos (1996) é elaborada com base nas seguintes orientaçóes:

Considerando que a Declaraçáo Universal dos Direitos do Homem de 1948 , (...) estabelece que "todos têm todos os direitos e todas as liberdades", sem distinção "de raça, cor, sexo, língua, religião, opinião política ou outra, origem nacional ou social, fortuna, nascimento ou qualquer outra condiçáa"; (...) Considerando a Resoluçấo 47/135, de 18 de Dezembro de 1992, da Assembléia Geral da Organização das Naçóes Unidas, que adota a Declaração sobre os direitos das pessoas pertencentes a minorias nacionais ou étnicas, religiosas e linguísticas; (...) Considerando que na Declaração do Recife (Brasil), de 9 de Outubro de 1987, o XXII Seminário da Associação Internacional para o Desenvolvimento da Comunicação Intercultural recomenda às Naçóes Unidas que tomem as medidas necessárias à adoção e aplicação de uma Declaração Universal dos Direitos Linguísticos; Considerando a Convenção número 169 da Organizaçáo Internacional do Trabalho, de 26 de Junho de 1989, relativa aos povos indígenas em países independentes; Considerando que a Declaração Universal dos Direitos Coletivos dos Povos, aprovada em Maio de 1990 em Barcelona, declara que todos os povos têm direito a exprimir e a desenvolver a sua cultura, a sua língua e as suas normas de organizaçáo e, para o fazerem, a dotarem-se de estruturas políticas, educativas, de comunicação e de administração pública

${ }^{1}$ Mantivemos a expressáo "linguagem de signos", empregada na Declaração de Salamanca (1994), ao invés da expressão utilizada atualmente (língua de sinais). 
próprias, em quadros políticos diferentes; (...) Considerando o relatório da Comissão dos Direitos Humanos do Conselho Económico e Social das Naçốes Unidas, de 20 de Abril de 1994, sobre o texto provisório da Declaração dos Direitos dos Povos Indígenas, declaração em que os direitos individuais são considerados à luz dos direitos coletivos (UNESCO, 1996).

Verifica-se que as línguas de sinais são parte da história e da cultura do Povo Surdo. Para Strobel (2013), Povo Surdo é o grupo de sujeitos que possuem costumes, histórias, tradiçóes em comum e são produtores de suas concepçôes do mundo através da visão. Perlin (2015), ao descrever o Povo Surdo, acrescenta que ao surdo pertence à experiência visual do mundo e não auditiva.

\section{Análise de dados}

Nesta seção, a fim de compreender políticas linguísticas das sete línguas que compóem este estudo, são analisados marcos legais a respeito das seguintes línguas de sinais: Língua de Sinais Francesa; Língua de Sinais Americana; Língua de Sinais Sueca; Língua Gestual Portuguesa; Língua de Sinais Japonesa; Língua de Sinais Chinesa; Língua Brasileira de Sinais. Assim, para compor a análise de dados, foram consultados marcos legais escritos em português (Brasil e Portugal), em francês (França) e em inglês (Estados Unidos da América). Foram consultados também marcos legais escritos em inglês referente às línguas de sinais da Suécia, da China e do Japão.

\section{Língua de Sinais Francesa}

Em relação às políticas linguísticas sobre a Língua de Sinais Francesa (LSF) e sobre os direitos dos surdos na França, a Lei 91-73, de 18 de janeiro de 1991, reconhece que as famílias têm o direito de escolher uma educação bilíngue (Língua de Sinais Francesa - Língua Francesa) na educação de filhos surdos. Em 1998, o relatório Gillot sobre "os direitos dos surdos" (A Lei dos Surdos - 115 propostas: relatório ao Primeiro Ministro) indicou que, apesar da publicação da legislação anterior, este direito não foi respeitado. Apenas um por cento dos estudantes surdos tinha acesso às estruturas bilíngues. Esse relatório também destacou grande índice de analfabetismo entre os surdos. 
Sete anos depois, a Lei 2005-102, de 11 de fevereiro de 2005, institui "questôes referentes à acessibilidade no tocante à escolaridade no ensino superior e no curso profissionalizante" (MENDES; ALMEIDA, 2010, p. 51). $\mathrm{O}$ artigo 19 estabelece que o Estado determina recursos financeiros e humanos necessários para a escolaridade nas escolas comuns. $\mathrm{O}$ artigo 20 especifica as mesmas obrigaçóes para o ensino superior. $\mathrm{O}$ artigo 76 da referida Lei esclarece que, antes dos tribunais administrativos, civis e criminais, qualquer surdo beneficia-se do dispositivo de comunicação adaptado de sua escolha, sendo os custos financiados pelo Estado. No artigo 77, a fim de garantir a livre circulação e adaptação de testes de licença de conduçáo para surdos e com deficiência auditiva, um intérprete estará presente nas provas teóricas e práticas da carteira de condução para veículos leves (licença B). E o artigo 78 descreve serviço de telefonia para deficientes auditivos.

Em 2008, são acrescentados ao artigo 93-3, da Lei de 2005, o reconhecimento e a difusão da Língua de Sinais Francesa em Mayotte, Nova Caledônia, Polinésia Francesa e Wallis e Futuna². Dessa forma, esses instrumentos linguísticos legais contribuem para a divulgação da Língua de Sinais Francesa, para a profissão de intérpretes e para os direitos dos cidadáos surdos franceses. Vale ressaltar que, segundo Cloix (2010), embora a LSF seja reconhecida ainda persistem debates sobre educação de surdos e a relação com a língua de sinais na França.

\section{Língua de Sinais Americana}

Segundo Rocha (2008), o americano Thomas Hopkins Gallaudet viajou para a Europa a fim de aprender mais sobre a educação de surdos. Em Londres, em 1816, Thomas Hopkins Gallaudet conheceu o abade francês Sicard, sucessor do abade L'Épée (diretor do Instituto Real para surdos em Paris), que estava com alunos surdos, dentre eles, Laurent Clerc. Laurent Clerc apresentou desempenho com método usado em Paris por meio de sinais da Língua de Sinais Francesa (LSF). Sicard convidou Thomas Hopkins Gallaudet para visitar o Instituto Real para surdos.

Posteriormente, Gallaudet retornou aos Estados Unidos da America

${ }^{2}$ Os lugares mencionados não fazerem parte do território francês conhecido como hexágono. Cabe ressaltar que o formato geográfico da França é conhecido como hexágono devido à representação do país ser parecida ao formato de um polígono com seis lados paralelos representando três costas e três fronteiras terrestres. 
com Laurent Clerc. Gallaudet e Clerc fundaram a primeira escola para surdos nos Estados Unidos da América, em Connecticut, em 1817: asilo para educação e instrução de surdos e mudos. Atualmente, essa instituição recebeu o nome de Escola Americana para Surdos. Em 1957, Edward Gallaudet, filho de Thomas Gallaudet, tornou-se diretor da Instituição de Columbia para Instrução de Surdos, Surdos e Cegos. Em 1964, com o apoio federal, tornou-se a Universidade de Gallaudet, primeira universidade para surdos no mundo.

Outro marco para a comunidade surda, em relação às línguas de sinais, foi a contribuição, em 1960, de William Stokoe para o reconhecimento da ASL como língua. Em decorrência desse acontecimento, houve um

\begin{abstract}
impulso na década de 1970 para o reconhecimento da ASL como língua aos olhos da comunidade ouvinte. A fim de alcançar legitimidade, ASL tinha de encontrar o mesmo critério para a arbitrariedade que línguas faladas exibiam - a relaçáo entre um elemento significativo na linguagem e sua denotaçáo deve ser independente de qualquer semelhança física entre os dois (WILCOX, 2000, p. 36) ${ }^{3}$.
\end{abstract}

Acerca das leis federais nos Estados Unidos da América sobre o atendimento ao surdo e também a respeito do uso da Língua de Sinais Americana, destacamos as Emendas da Lei de reabilitação profissional, em 8 de novembro de 1965, que motivaram a publicação de outros marcos legais. A Lei Federal 89 - 333 foi promulgada especificando serviços para cegos e surdos, descrevendo a necessidade de leitores para cegos e intérpretes para surdos. Com essa resolução, há a identificação da atividade profissional de interpretação de língua de sinais para clientes surdos.

Em 26 de setembro de 1973, foi aprovada a Lei 93-112 (Lei de reabilitação) a respeito das responsabilidades federais dos programas de treinamento e pesquisa sobre pessoas com deficiência a fim de estabelecer responsabilidades para as Secretarias de Saúde, de Educação e de Bem-estar. Nessa lei, a função do intérprete é retomada na seção 103, descrevendo o atendimento aos surdos.

Em 29 de novembro de 1975, a Lei 94-142 (Lei de educação

\footnotetext{
${ }^{3}$ The push in the late 1970s was for recognition of ASL as a language in the eyes of the hearing community. In order to achieve legitimacy, ASL had to meet the same criterion for arbitrariness that spoken languages exhibit - the relationship between a meaningful element in language and its denotation must be independent of any physical resemblance between the two [traduçáo da autora].
} 
para todas as crianças com deficiência) providencia normas a respeito de assistência educacional para crianças com deficiência tendo em vista que nessa época, conforme seção 601, nos Estados Unidos havia mais de oito milhóes de crianças com necessidades especiais. Desse percentual, mais da metade não recebia educaçáo adequada. Esses atos deram origem à Lei de Educação de Indivíduos com Deficiências e à Lei dos Americanos com Deficiência, em 1990, cujos objetivos eram especificar direitos e deveres das pessoas com deficiência.

Em 8 de fevereiro de 1996, a Lei 104-104 (Lei de telecomunicaçôes) foi decretada instituindo normas de qualidade dos serviços de telecomunicaçóes prestados aos consumidores e promovendo diretrizes para garantir acessibilidade. Em 2001, com a Lei 107-110 (Nenhuma criança deixada para trás), são relatadas ações para garantir a acessibilidade na formação educacional de pessoas com deficiência, indígenas e imigrantes, incluindo a participação dos pais dessas crianças no processo escolar. Essas legislaçôes acabam apontando para a realidade linguística dos surdos nos Estados Unidos da América, mostrando a presença de intérpretes e de legendas para surdos em programas de TV.

Segundo Meulder (2015), a Língua de Sinais Americana (ASL) e a Língua de Sinais Québécoise (LSQ) no Canadá ainda não foram reconhecidas em nível federal, mas há menção dessas línguas em legislações estaduais ou provincial. A autora afirma que

várias províncias canadenses reconheceram legislativamente ASL ou LSQ como uma língua de instrução. Nos Estados Unidos, quarenta estados reconhecem a ASL como língua, e vários a reconheceram como língua (estrangeira) para fins educacionais (MEÜLDER, 2015, p. 505) ${ }^{4}$.

Assim, a ASL vem ganhando reconhecimento em estados americanos, conforme listagem de relação de estados dos Estados Unidos da América que reconheceram a ASL, disponível no acervo da biblioteca online da Universidade de Gallaudet, fornecida pelo Conselho Nacional de Supervisores Estaduais de Idiomas 5 .

${ }^{4}$ Several Canadian provinces have legislatively recognized ASL or LSQ as a language of instruction. In the United States, forty states have recognized ASL as a language, and a number have recognized it as a (foreign) language for educational purposes [tradução da autora].

${ }^{5}$ Disponível na biblioteca online da Universidade de Gallaudet (Disponível em: shttp:// libguides.gallaudet. edu/content.php?pid $=114804 \&$ Sid $=991858>$. Acesso em: jun. 2020) fornecida pelo National Council of State Supervisors for Languages (Disponível em: $\leq$ http:// 


\section{Língua de Sinais Sueca}

Segundo Nilsson e Schönström (2014), a Suécia é o primeiro país no mundo a reconhecer uma língua de sinais. A Língua de Sinais Sueca LSS (Svenskt teckenspråk) - foi reconhecida como primeira língua dos surdos suecos em 14 de maio de 1981, proporcionando o bilinguismo para crianças surdas, ou seja, a Língua de Sinais Sueca como primeira língua e a Língua Sueca como segunda língua (SVARTHOLM, 2014). Há registros do uso da Língua de Sinais Sueca desde 1800, com a primeira escola para surdos em 1809 .

Desde 1906, a Associação Nacional Sueca de Surdos vem desenvolvendo açóes no país para promover a língua de sinais. Atualmente, o Departamento de Linguística da Universidade de Stockholm desenvolve pesquisas sobre essa língua de sinais. Em primeiro de agosto de 2009, a língua de sinais recebe o status de língua (Lei Nacional das Minorias e das Línguas Minoritárias). Esse documento descreve a política linguística estabelecida na Suécia esclarecendo que a Língua Sueca é a principal língua na Suécia ( $4 \$$ O sueco é o principal idioma da Suécia). Esse ato determina diretrizes a respeito da Língua Sueca, das línguas nacionais minoritárias e da Língua de Sinais Sueca destacando as responsabilidades do poder público para o acesso à comunicação. Também se especificam os usos da Língua Sueca no setor público e no contexto internacional.

Assim, cabe ao poder público ter a responsabilidade particular de proteger e promover a Língua de Sinais Sueca $(9 \$$ O público em geral tem uma responsabilidade especial de proteger e promover a língua de sinais sueca). Nesse ato, é instituído que todos os moradores da Suécia têm a oportunidade de aprender e desenvolver a Língua Sueca. Acrescenta-se que pessoas pertencentes a uma nacionalidade minoritária têm a oportunidade de aprender, desenvolver e usar sua língua minoritária. Em relação à Língua de Sinais Sueca,

pessoas surdas ou com perdas auditivas e pessoas, que por outras razóes aprendem a língua de sinais, devem ter o direito à oportunidade de aprender, desenvolver e usar a Língua de Sinais Sueca (Código do Estatutos Sueco no: 2009:600, $14 \$)^{6}$.

ncssfl.org/view-state-report/\#>. Acesso em: jun. 2020).

${ }^{6}$ den som är döv eller hörselskadad och den som av andra skäl har behov av teckenspråk ges möjlighet att lära sig, utveckla och använda det svenska teckenspråket [tradução da autora]. 
De acordo com essa proposta, instituiçóes públicas têm como incumbência promover e proteger a Língua de Sinais Sueca.

\title{
Língua Gestual Portuguesa
}

Sobre a Língua Gestual Portuguesa - LGP, Correia (2014) descreve que a

\begin{abstract}
Língua Gestual Sueca é considerada a língua-mãe da LGP uma vez que no século XIX o rei D. João VI, a pedido de sua filha, D. Isabel Maria, mandou chamar a Portugal o professor sueco Per Aron Borg que havia fundado em Estocolmo um instituto para a educação de surdos. Assim, em 1823, cria-se em Portugal a primeira escola para surdos onde lecionaram, a princípio, Per Aron Borg e seu irmão Joahan Borg (CORREIA, 2014, p. 162).
\end{abstract}

Per Aron Borg, pedagogo sueco, ajudou a fundar escola de surdos em Lisboa, sendo a Língua Gestual Portuguesa influenciada pela Língua de Sinais Sueca (WOLL; SUTTON-SPENCE; ELTON, 2001). Segundo Ferreira (2013), em 1834, inaugura-se o Instituto Jacob Rodrigues Pereira (IJRP) em Portugal com o foco na educação de crianças surdas. A princípio, esse instituto, com nome do educador de surdos francês que defendia a prática do oralismo, proibia em todos os estabelecimentos de ensino o uso de gestos e dava preferência ao método oral.

Segundo Duarte e Almeida (2003), em 1995, a Associação Portuguesa de Surdos (ASP), fundada em 1958, deu início aos debates sobre a necessidade de reconhecimento legal da Língua Gestual Portuguesa. Foi criada comissão para Reconhecimento e Proteçáo da Língua Gestual Portuguesa formada por cinco grupos: ASP, Associação de Intérpretes, Associação de pais, Associação de professores e Federação Portuguesa de Associação de surdos.

Em 1997, a Língua Gestual Portuguesa tem seu reconhecimento legal na Constituição da República Portuguesa. Foi instituído ao Estado "Proteger e valorizar a Língua Gestual Portuguesa, enquanto expressáo cultural e instrumento de acesso à educação e da igualdade de oportunidades" (Série A - n. 218 - 20/09/1997 - Lei Constitucional, Artigo 740 - alínea h). Consoante a Duarte e Almeida (2003), em 6 de maio de 1998, foi decretada lei do Ministério da Educaçáo reconhecendo a necessidade de professores de língua de sinais, de intérpretes e de professores para crianças e jovens surdos, que se comunicassem por língua de sinais. 
Conforme Aquiline (2003), em 14 de julho de 1998, surgiu lei com recomendaçôes sobre intérprete de língua de sinais, legendas e programas para a comunidade surda na televisão. Em 19 de março de 1999, o governo deu início a um projeto sobre legendas na televisão. Em 5 de julho de 1999, foi instituída lei que reconhecia e regularizava a profissão de intérpretes de língua de sinais. Em 11 de fevereiro de 2002, houve novamente lei para reforçar os direitos da pessoa surda de acessar às informaçóes veiculadas na TV pela língua de sinais e por legendas.

\section{Língua de Sinais Japonesa}

Consoante os estudos de McClue (2013), em 1970, a língua de sinais apareceu pela primeira vez em uma lei japonesa durante a revisão de lei sobre pessoas com deficiências. Em 1991, foi criada a Associação Japonesa de Intérpretes de Línguas de Sinais. Em 1997, o código de ética dessa associação foi estabelecido. Em 2002, foram fundadas a Federaçáo Japonesa de Surdos e a Associação Nacional de Pesquisa para Interpretação de Língua de Sinais.

McClue (2013) acrescenta que, em 2003, pais de surdos enviaram ao Ministério da Educação Japonês uma petição para a LSJ ser a língua de instrução de surdos, tendo em vista que professores e alunos surdos, muitas vezes, não conseguiam compreender uns aos outros. O Ministério da Educação, retomando a filosofia do Congresso de Miláo em 1880, reafirmou a educação de surdos com base no oralismo e descreveu que outras formas de comunicação poderiam ser ensinadas depois. Em 2011, foi promulgado o Ato Básico para Pessoas com Deficiência cujo texto descreve que

são garantidas a todas as pessoas com deficiência a oportunidade, na medida do possível, de escolher a sua língua (incluindo a língua de sinais) e outros meios de comunicação para a compreensão mútua; e as oportunidades para eles escolherem os meios de aquisição ou uso de informaçóes que serão expandidas (ATO BÁSICO PARA PESSOAS COM DEFICIÊNCIA, ITEM III, 2011) 7 .

Sobre a LSJ, ressalta-se que a família da Língua de Sinais Japonesa

${ }^{7}$ All persons with disabilities are guaranteed the opportunity, insofar as possible, to choose their language (including sign language) and other means of communication for mutual understanding; and opportunities for them to choose the means of acquisition or use of information will be expanded [tradução da autora]. 
inclui a Língua de Sinais de Taiwan e a Língua de Sinais Coreana. A Língua de Sinais Japonesa - LSJ é conhecida como Nihon Shuwa e, antigamente, outro termo bastante usado para a Língua de Sinais era Temane (EBERHARD; GARY; CHARLES, 2020).

\section{Língua de Sinais Chinesa}

Na Língua de Sinais Chinesa, segundo Yang (2008), o primeiro registro histórico do uso de sinais para comunicação remonta à Dinastia Tang (A.C. 618-959) em que a palavra chinesa 手语 Shou-yu (linguagem gestual) aparece na literatura. Shou-yu era usado para se referir a uma comunicação manual envolvendo sinais icônicos. A existência de uma comunidade que usasse sinais foi mencionada durante a Dinastia Song do Norte (960-1127) de Su Dongpo, no documento Guaishi Ji, sobre categorias e origens de línguas de sinais (MU, 1991 apud PUTS; LÓPEZ, 2008).

Há diversos dialetos da LSC na China. Locais como Shanghai, Nanjing, Beijing e Tianjin usam suas próprias variaçóes. Entretanto, a moderna Língua de Sinais Chinesa - LSC (Zhongguo Shouyu) desenvolveuse no final dos anos de 1950. Em 1959, publicou-se o primeiro alfabeto fonético manual da Língua de Sinais Chinesa moderna, constituído por um total de 30 configuraçóes de máo. Com o objetivo de estabelecer um léxico CSL unificado, compilou-se um conjunto de léxico de quatro volumes intitulado "Padronização de sinais para surdos", em 1961, que foi oficialmente publicado em 1963 e continha não só muitos itens lexicais regionais, mas também sinais emprestados do International Sign System. Em 1990, ocorreu a publicação de lei sobre proteção a pessoas com deficiência, mencionando a língua de sinais na China:

Artigo 26. Os serviços governamentais interessados devem organizar e apoiar a pesquisa e aplicaçáo do braille e da língua de sinais, a compilação, escrita e publicação de material didático de educaçáo especial e a pesquisa, produção e fornecimento de aparatos didáticos e outras instalaçóes auxiliares para educação especial (LEI DA REPÚBLICA POPULAR DA CHINA SOBRE A PROTEÇÃO DAS PESSOAS DEFICIENTES, 1990, Artigo 26) ${ }^{8}$.

${ }^{8}$ Article 26. Governmental departments concerned shall organize and support the research and application of Braille and sign language, the compilation, writing and publication of special education teaching materials and the research, production and supply of teaching apparatus and other auxiliary facilities for special education [traduçáo da autora]. 
O referido artigo promove o incentivo à produção de material didático e também à pesquisa sobre línguas de sinais e Sistema Braille, reconhecendo a existência de língua de sinais no país.

\section{Língua Brasileira de Sinais}

Segundo Rocha (2008), em 1857, foi criado, no Rio de Janeiro, Brasil, o Imperial Instituto dos Surdos-Mudos, por meio dos esforços de Édouard Huet, professor surdo francês, com a aprovação de Dom Pedro II (Lei n. ${ }^{0} 939$ de 26 de setembro de 1857). A escola era destinada à educação de surdos de sete a catorze anos, atualmente, conhecida como Instituto Nacional de Educação de Surdos - INES.

Huet tinha como base a Língua de Sinais Francesa - LSF para os estudos no Brasil. Daí o fato de a Língua Brasileira de Sinais - Libras ter influência da LSF, conforme afirma Dsecours que "a influência francesa é, portanto, muito clara na educação dos surdos brasileiros" (DESCOURS, 2011, p. 33) ${ }^{9}$. Cabe ressaltar que Brito 2010 [1995] pesquisou a existência no Brasil da Língua de Sinais Kaapor Brasileira (LSKB), praticada por índios da tribo Urubu-Kaapor, e a Língua de Sinais dos Centros Urbanos Brasileiros (LSCB). A LSCB ficou conhecida como a Língua Brasileira de Sinais - LSB/Libras.

A Libras teve seu reconhecimento legal no Brasil em 2002 com a publicaçáo da Lei no $\mathbf{1 0 . 4 3 6}$, de 24 de abril de 2002, que descreve a Libras como meio legal de comunicaçáo e expressáo. A Língua Brasileira de Sinais é entendida como

a forma de comunicação e expressão, em que o sistema linguístico de natureza visual-motora, com estrutura gramatical própria, constituem um sistema linguístico de transmissão de ideias e fatos, oriundos de comunidades de pessoas surdas do Brasil (PARÁGRAFO ÚNICO, LEI 10.436/2002).

Essa lei também propóe a inclusão do ensino de Libras nos cursos de fonoaudiologia e de magistérios, no Ensino Médio e no Ensino Superior.

O Decreto n. ${ }^{0}$ 5. 626/2005 regulamenta a Lei n. ${ }^{0}$ 10.436/2002, descrevendo a pessoa surda, classificando tipos de perdas auditivas,

9'influence francaise est donc tres nette dans l'education des sourds bresiliens et meme dans leurs gestes: utilisation de la LSF [traduçâo da autora]. 
detalhando a inclusão da matéria de Libras, a formação de professores e instrutores de Libras e a regulamentação do Exame Nacional de Proficiência em Libras (PROLIBRAS) para a interpretaçáo/tradução e para o ensino.

O Decreto n. ${ }^{0}$ 6.949/2009 promove, protege e assegura o exercício pleno e equitativo de todos os direitos humanos, viabilizando a facilitação do aprendizado da língua de sinais e a promoção da identidade linguística da comunidade surda.

A Lei n. ${ }^{0}$ 12. 319/2010 especifica a formaçáo, as atribuiçóes e as competências do profissional tradutor e intérprete da Libras.

O Decreto 7.387/2010 institui o Inventário Nacional da Diversidade Linguística e se propóe a mapear, a caracterizar e a diagnosticar as diferentes situaçôes relacionadas à pluralidade linguística brasileira.

A Lei n. ${ }^{0}$ 13.0005/2014 expóe o Plano Nacional de Educação - PNE, cuja apresentaçáo de metas detalha o atendimento educacional especializado e a proposta de expansão de obras didáticas em Libras e no Sistema Braille. Segundo Neves (2015), o PNE coloca como prioridade a educação de surdos em escolas bilíngues e prenuncia a formação de profissionais.

A Lei n. ${ }^{0}$ 13.146/2015 institui a Lei Brasileira de Inclusão da Pessoa com Deficiência (Estatuto da Pessoa com Deficiência) fazendo alusão à educação bilíngue e à atuação de intérpretes.

\section{Consideraçóes Finais}

Diretrizes legais são registros históricos, linguísticos e políticos ligados diretamente à língua e aos seus usuários, contribuindo para a descrição da língua de sinais e também para o modo como os sujeitos surdos são vistos na sociedade. Em relação à História das Ideias Linguísticas, tais diretrizes são consideradas instrumentos linguísticos no processo de institucionalizar as línguas de sinais.

A aprovação dessas resoluçóes garante ao Povo Surdo seu direito linguístico e cultural respeitado. Dos países analisados, apenas Portugal reconheceu a língua de sinais na constituiçáo explicitando a responsabilidade do Estado de proteger e valorizar a Língua Gestual Portuguesa, como meio de expressão cultural e de acesso à educação e à igualdade de oportunidades.

Com base nos marcos legais de sete países analisados, descrevemos algumas considerações. A Suécia apresentou reconhecimento da língua em 
1981 e ampliou em 2009 esse fato destacando legalmente a necessidade do poder público ter o comprometimento particular de proteger e promover a Língua de Sinais Sueca. No Brasil, há resoluçôes legais para o reconhecimento e a difusão da Libras, sendo a profissão de intérpretes assegurada e a inclusão dessa língua de sinais no processo de formação de professores e fonoaudiólogos. A França reconheceu o direito de as famílias escolherem por uma educação bilíngue (Língua de Sinais Francesa - Língua Francesa) na educação de filhos surdos e promoveu a difusão da LSF em cidades da França.

Já os Estados Unidos da América, com diversas leis em âmbito nacional sobre políticas relacionadas às pessoas com deficiência, legitimam o uso da língua de sinais e a presença de intérpretes. Entretanto, apenas em alguns estados norte-americanos, a Língua de Sinais Americana é de fato reconhecida. Japão e China também apresentam as línguas de sinais de seus países em deliberaçóes acerca de pessoas com deficiência, assegurando o uso da língua de sinais e a presença de intérpretes em comunicaçóes com surdos.

Verificamos que marcos legais, como a regulamentação de leis e de decretos, contribuem para estabelecer relaçóes entre uma língua e seus usuários. Ao descrever em um documento oficial, tais marcos apontam para como essa língua será usada e ensinada em uma sociedade. Esses documentos são instrumentos de poder social e contribuem para a descrição linguística de uma língua.

Diante desses fatos, foi constatado também que as línguas de sinais estão sendo reconhecidas mundialmente, logo, a cultura do Povo Surdo também está sendo difundida. Todavia, ainda náo se verifica uma oficialização dessas línguas que possa garantir ao surdo o direito de expressarse e de ser compreendido em todas as áreas da sociedade usando apenas a língua de sinais, pois a língua oral desses países permanece como status legal de autoridade para educar, registrar, comunicar e realizar transaçôes oficiais. Sendo assim, ainda é preciso desenvolver políticas linguísticas que possam assegurar aos surdos direitos linguísticos de acessar e de produzir conhecimento, que possa também ser oficializados em língua de sinais.

\section{Referências}

AMERICAN'S WITH DISABILITIES ACT - ADA. Disponível em: $<$ https://www.dol.gov/oasam/programs/crc/ADA-1990.pdf>. Acesso em: 
27 dez. 2017.

ANTUNES, Irandé Costa. Muito além da gramática: Por um ensino sem pedras no caminho. 1. ed. Belo Horizonte: Parábola, 2007.

AQUILINE, Carol-lee. Sign Language Recognition. Magazine of the World Federation of the Deaf - WDF. v. 16. n. 2, p. 07-08, jul. 2003. Disponível em: https://core.ac.uk/download/pdf/62692087.pdf. Acesso em: 16 abr. 2020.

AUROUX, S. A revoluçáo tecnológica da gramatizaçáo. Trad. Eni Puccinelli Orlandi. Campinas: Unicamp, 1992.

BASIC ACT FOR PERSONS WITH DISABILITIES. Disponível em: <http://www.japaneselawtranslation.go.jp/law/ detail/?id=2436\&vm=04\&re=02 $>$. Acesso em: $19 \mathrm{dez} .2017$.

BAUER, Carlos (Org). Teoria da história. A Educação no Brasil. São Paulo: Capo Editorial, 2012.

BLOCH, Marc. Apologia da História ou O ofício do Historiador. Rio de Janeiro: Jorge Zahar, 2001. p. 52-55. Disponível em: https:// bibliotecaonlinedahisfi. files.wordpress.com/2015/02/bloch-m-apologiada-histc3b3ria.pdf. Acesso em: 27 jun. 2020.

BRASIL. Lei n 10.098, de 19 de dezembro de 2000. Estabelece normas gerais e critérios básicos para a promoção da acessibilidade das pessoas portadoras de deficiência ou com mobilidade reduzida, e dá outras providências. Brasília, 2000.

. Lei $\mathrm{n}^{\circ}$ 10.436, 24 de abril de 2002. Dispóe sobre a Língua Brasileira de Sinais - Libras e dá outras providências. Brasília, 2002.

. Decreto $\mathrm{n}^{\circ} \mathbf{5 . 6 2 6}$, de 22 de dezembro de 2005. Regulamenta a Lei $\mathrm{n}^{\circ} 10.436$, de 24 de abril de 2002, que dispóe sobre a Língua Brasileira de Sinais- Libras, e o art. 18 da Lei n ${ }^{\circ} 10.098$, de 19 de dezembro de 2000. Brasília, 2005.

- Decreto $\mathrm{n}^{\circ}$ 6.949, de 25 de agosto de 2009. Promulga a Convenção Internacional sobre os Direitos das Pessoas com Deficiência e seu Protocolo Facultativo, assinados em Nova York, em 30 de março de 2007. Brasília, 2009.

Lei $\mathrm{n}^{\circ} 12.319,1^{\circ}$ de setembro de 2010. Regulamenta a profissão de Tradutor e Intérprete da Língua Brasileira de Sinais - LIBRAS. Brasília, 2010 .

Decreto no 7.387, de 9 de dezembro de 2010. Institui o 
Inventário Nacional da Diversidade Linguística e dá outras providências. Brasília, 2010. . Lei $\mathrm{n}^{\circ} 13.005$, de 25 de junho de 2014. Aprova o Plano Nacional de Educação - PNE e dá outras providências. Brasília, 2014., Brasília, DF.

Lei no 13.146, de 6 de julho de 2015. Institui a Lei Brasileira de Inclusão da Pessoa com Deficiência (Estatuto da Pessoa com Deficiência). Brasília, 2015.

BRITO, Lucinda Ferreira. Por uma gramática de língua de sinais. Rio de Janeiro: Tempo Brasileiro, 2010 [1995].

CLOIX, Margaux. Lapprentissage de la Langue des Signes Française chez les sujets entendants: quelles sont les difficultés à maîtriser une langue gestuelle?. France, Gières: Université Stendhal, 2010.

CONSTANTINO, Núncia Santoro de. Benedetto Croce. In: MALERBA, Jurandir (Org.). Liçóes de História. Da história científica à crise da razão metódica no limiar do século XX. Porto Alegre; Rio de Janeiro: Edipucrs; FGV, 2013. p. 273-295.

CORREIA, Isabel Sofia Calvário. Morfologia derivacional em língua gestual portuguesa: alguns exemplos. Educação e Formação. Exedra, Revista científica, n. 9, p. 162-163, 2014.

DECLARAÇÃO DE SALAMANCA. Sobre princípios, políticas e práticas na área das necessidades educativas especiais. Disponível em: $<$ http://portal. mec. gov.br/seesp/arquivos /pdf/salamanca.pdf>. Acesso em: 16 abr. 2020.

DESCOURS, Pauline. L'histoire de la langue des signes française et de la langue des signes bresilienne: quelles inuences pour les populations sourdes? Linguistique, Année universitaire 2010-2011, 2011. p. 32-33. Disponível em: <https://dumas.ccsd.cnrs.fr/dumas-00603905>. Acesso em: 28 mai. 2020.

DUARTE, Helder; ALMEIDA, Maria Jose. PORTUGAL Recognizing and Protecting Sign Language in the Constitution. Magazine of the World Federation Deaf. v. 16. n. 2, p. 07-08, jul. 2003.

EBERHARD, David M.; GARY, F. Simons; CHARLES D. Fenning (Eds). Ethnologue: Languages of the World. 23. ed. Dallas, Texas: SIL International, 2020. Disponível em: $<$ http://www.ethnologue.com $>$. Acesso em: 15 abr. 2020.

EDUCATION FOR ALL HANDICAPPED CHILDREN ACT OF 1975. Disponível em: <https://www.gpo.gov/fdsys/pkg/STATUTE-89/pdf/ 
STATUTE-89-Pg773.pdf>. Acesso em: 28 dez. 2017.

FERREIRA, Sara Raquel Pinheiro Santos. Sensibilizaçáo à Língua Gestual Portuguesa: um estudo no $1 .^{\circ}$ ciclo. (Dissertaçáo) Mestre em Ensino, Universidade de Aveiro, 2013.

FÁVERO, Leonor Lopes; MOLINA, Márcia A. G. História das ideias linguística: origem, método e limitações. Anpoll, n. 16, p. 136-137, jan./ jun. 2004.

GALLO, S. Discurso da Escrita e Ensino. Campinas: Unicamp, 1993.

GERHARDT, Tatiana Engel; SILVEIRA, Denise Tolfo. Métodos de pesquisa. Universidade Aberta do Brasil - UAB/UFRGS. Porto Alegre: UFRGS, 2009.

GILLOT, Dominique. Le Droit des sourds: 115 propositions : rapport au Premier ministre. Disponível em: <http://www.ladocumentationfrancaise. fr/rapportspublics/984001595/index.shtml>. Acesso em: 19 dez. 2017.

GUIMARÁES, E. R. J.; ORLANDI, E. P. Formação de um espaço de produção linguística. A gramatica no Brasil. In: GUIMARÃES, Eduardo Robertro Junqueira. (Org.). Historia das Ideias Linguísticas: construção do saber metalinguístico. Campinas: Pontes, 2001. p. 32-33.

LAKATOS, I. History of science and its rational reconstructions. In: HACKING, I. (Org.). Scientific revolutions. Hong-Kong: Oxford University, 1983. p. 116-117.

LAW OF THE PEOPLE' $S$ REPUBLIC OF CHINA ON THE PROTECTION OF DISABLED PERSONS. 1990. Disponível em: $<$ http://www1.lawinfochina. com/Display.aspx?lib=law\&Cgid=4924\#>. Acesso em: 19 dez. 2017.

LOI 9173 (TITRE III) ARTICLE 33 DU 18 JANVIER 1991. Disponível em: <https://www.2lpe.fr/wp-content/uploads/2017/04/loi-janvier-1991autorisant-lebilinguisme. pdf > Acesso em: 19 dez. 2017.

LOI N 2005-102 DU 11 FÉVRIER 2005. Pour l'égalité des droits et des chances, la participation et la citoyenneté des personnes handicapées. Disponível em: <https://www.legifrance.gouv.fr/affichTexte. do?cidTexte=JORFTEXT000000809647> . Acesso em: 19 dez. 2017.

MCCLUE, Patrick. Setting the Standard: An Overview of the History and Politics of Prohibiting and Promoting a National Japanese Sign Language. CiNii. n. 63, v. 2, p. 207-220, 2013. Disponível em: https://ci.nii.ac.jp/ author?q=MCCLUE+Patrick. Acesso em: 19 dez. 2017. 
MENDES, Enicéia Gonçalves; ALMEIDA, Maria Amélia (Org). Das margens ao centro: perspectivas para as políticas e práticas educacionais no contexto da educação inclusiva. São Paulo: Junqueira e Marin, 2010.

MEULDER, Maartje de. The Legal Recognition of Sign Languages. Sign Language Studies. Gallaudet University Press. v. 15, n. 4, p. 498-506, 2015.

NEVES, Bruna Clemêncio. O Brasil é um país bilíngue: a cooficialização da Libras. In: MORELLO, Rosângela (Org.). Leis e línguas no Brasil: o processo de cooficialização e suas potencialidades. Florianópolis: IPOL, 2015. p. 140-141.

NO CHILD LEFT BEHIND ACT OF 2001. Disponível em: <https:// www2.ed.gov/ admins/lead/ account/nclbreference/reference.pdf $>$. Acesso em: 27 dez. 2017.

OLIVEIRA, Ana Fernanda Inocente. O sentido da história para a École des Annales. Tese (Doutorado em Sociologia). Universidade Estadual Paulista - UNESP, Araraquera, São Paulo, 2014.

ORLANDI, Eni Puccinelli. História das ideias linguísticas: construção do saber metalinguístico e constituição da língua nacional. São Paulo: Pontes, 2001.p. 09-10.

NILSSON, Anna-Lena; SCHÖNSTRÖM, Krister. Swedish Sign Language as a Second Language: Historical and Contemporary Perspectives. In: MCKEE, D.; ROSEN, R. S.; MCKEE, R. (Eds.). Teaching and Learning Signed Languages. Palgrave Macmillan, London, 2014. p. 11-34.

NUNES, José Horta. Dicionários: história, leitura e produção. Revista de Letras (Taguatinga), Brasília, UCB, v. 3, p. 06-20, 2010.

NUNES, Valeria Fernandes. Corporificação e iconicidade cognitiva: um estudo sobre verbos em línguas de sinais. Tese (Doutorado em Linguística) - Instituto de Letras, Universidade do Estado do Rio de Janeiro, Rio de Janeiro, 2018.

PERLIN, Gládis; STROBEL, Karin. Teorias da Educaçáo e Estudos Surdos. Florianópolis: CCE/UFSC, 2009.

PUST, Carolina Plaza; LÓPEZ, Esperanza Morales. Sign Bilingualism: Language Development, Interaction, and Maintenance in sign language contact situation. Philadelphia: John Benjamins North America, 2008.

REHABILITATION ACT of 1973. Disponível em: < http://www2.pr.gov/ presupuestos /Presupuesto2013-2014/PresupuestosAgencias/suppdocs/ 
baselegal/126/act1973.pdf>. Acesso em: 28 dez. 2017.

ROCHA, Solange. O INES e a educaçáo de surdos no Brasil: aspectos da trajetória do Instituto Nacional de Educaçáo de surdos em seu percurso de 150 anos. v. 1, 2. ed. Rio de Janeiro: INES, 2008.

SILVA, Nilce Maria. Instrumentos linguísticos de Língua Brasileira de Sinais: constituição e formulação. Tese (doutorado) - Universidade Estadual de Campinas, Instituto de Estudos da Linguagem.Campinas, 2012.

STROBEL, Karin. As imagens do outro sobre a cultura surda. 3. ed. rev. Florianópolis: UFSC, 2013.

SVARTHOLM, Kristina. 35 anos de Educação Bilíngue de surdos - e então? Educar em Revista, Curitiba, Brasil, UFPR, Edição Especial, n. 2, p. 33-50, 2014.

SWEDISH CODE OF STATUTES NO: 2009:600. Disponível em Inglês em: <http://www.regeringen.se/ contentassets/9e56b0c78cb5447b968a29dd14a68358/spraklag-paengelska>. Disponível em Sueco em: <http://www.riksdagen.se/sv/ dokument-lagar/dokument/svensk-forfattningssamling/spraklag-2009600 sfs-2009-600 >. Acesso em: 19 dez. 2017.

TELECOMMUNICATIONS ACT OF 1996. Disponível em: $<\underline{\text { https:// }}$ legcounsel.house.gov/Comps/Telecommunications $\% 20$ Act $\% 20 \mathrm{Of} \% 20$ 1996.pdf>. Acesso: 27 dez. 2017.

THE INDIVIDUALS WITH DISABILITIES EDUCATION ACT IDEA. Disponível em: <https://www2.ed.gov/policy/speced/leg/idea/idea. pdf>. Acesso: 27 dez. 2017.

UNESCO. Coordenadoria Nacional para a Integração da Pessoa Portadora de Deficiência (CORDE). Declaraçáo de Salamanca de princípios, política e prática para as necessidades educativas especiais. Brasília: CORDE, 1994.

UNESCO. Declaraçáo Universal dos Direitos Linguísticos. Barcelona, 1996. Disponível em: $<$ file://C:/Users/Admin/Downloads/Declaracao\%20 Universal\%20dos\%20Direitos\%20 Linguisticos.pdf>. Acesso em: $30 \mathrm{dez}$. 2017.

VOCATIONAL REHABILITATION ACT AMENDMENTS OF 1965.

Disponível em: <https://www.gpo.gov/fdsys/pkg/STATUTE-79/pdf/ STATUTE-79-Pg1282.pdf>. Acesso em: 28 dez. 2017.

WILCOX, Phyllis Perrin. Metaphor in American Sign Language. 
Washington D.C.:

Gallaudet, University Press, 2000.

WOLL, Bencie; SUTTON-SPENCE, Rachel; ELTON, Frances. Multiculturalism: the global approach to sign languages. In: LUCAS, Ceil. The Sociolinguistics of Sign Language. Cambridge: Cambridge University Press, 2001. p. 08-10.

YANG, Jun Hui. Sign language and oral/written language in deaf education in China. In: PLAZA-PUST, Carolina; MORALES-LÓPEZ, Esperanza. Sign Bilingualism: Language development, interaction, and maintenance. John Benjamins Publishing Company, Amsterdam, Philadelphia, 2008. p. 297-331. 